\title{
Sterilization of propylene/ethylene random copolymers: Annealing effects on crystalline structure and transparency as influenced by polymer structure and nucleation
}

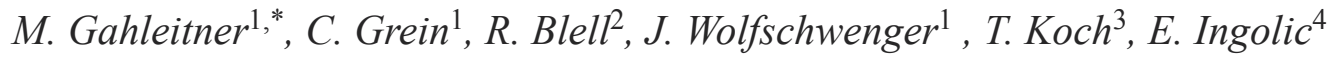 \\ ${ }^{1}$ Borealis Polyolefine GmbH, Innovation Headquarters Linz, St. Peterstr. 25, 4021 Linz, Austria \\ ${ }^{2}$ Institut Charles Sadron, UPR22, CNRS-ULP, 6 rue Boussingault, 67083 Strasbourg, France \\ ${ }^{3}$ Vienna University of Technology, Institute of Materials Science and Technology, Favoritenstraße 9-11, 1040 Vienna, \\ Austria \\ ${ }^{4}$ Institute for Electron Microscopy, Graz University of Technology, Steyrergasse 17, 8010 Graz, Austria
}

Received 5 January 2011; accepted in revised form 11 March 2011

\begin{abstract}
An extensive investigation of three different series of isotactic ethylene/propylene (EP) random copolymers was performed to understand the factors influencing the change in optical properties in the steam sterilization of extrusion cast films from such materials. Different analytical methods (differential scanning calorimetry (DSC), X-ray diffraction and electron microscopy) were employed to elucidate structural changes determining film optics, and in addition to the polymer structure parameters also nucleation and processing effects were studied. The findings clearly show that a combination of homogeneously randomized comonomer distribution and nucleation can partly inhibit lamellar thickening in sterilization, thus preserving high transparency even after a heat treatment. In detail, attention has to be paid to the combined effects of primary and secondary post-crystallization, which both are affected by the chain regularity.
\end{abstract}

Keywords: processing technologies, material testing, polypropylene, crystallization, optical properties

\section{Introduction}

Extrusion cast film, a major application area for polypropylene (PP), requires an excellent combination of mechanical and optical properties. Apart from homopolymers, ethylene-propylene (EP) random copolymers are the most important materials for this segment, taking advantage of their remarkable see-through performance. The good optical quality is a result of their slower crystallization speed compared to standard isotactic PP (iPP) resulting in less crystallinity and a finer crystal structure [1]. A growing fraction of this segment is subjected to pasteurization or sterilization processes, like in medical applications or food packaging. Radiation sterilization by $\gamma$-radiation or electron beam ( $\beta$-radiation) which is a normal and well established technology for polyethylene (PE) has been found to be critical for PP as it induces radical degradation processes and leads to massive toughness losses [2].

But also in steam sterilization which has been found to be generally suitable for PP, the mechanical and optical consequences of such a treatment must be considered in material design already [3], basically requiring an understanding of physical ageing and post-crystallization effects [4]. Several studies regarding controlled aging or annealing at different temperatures for various times have been performed on injection or compression moulded thick samples. Mechanical tests along with observation of the

${ }^{*}$ Corresponding author, e-mail: markus.gahleitner@borealisgroup.com (C) BME-PT 
microstructure at different scales have been done in order to follow the induced changes and understand their origin [5-7], but such results are of limited relevance for predicting the behaviour of films, especially with respect to an alteration of the optical properties after a defined heat treatment.

In this special case the crystal structure originally generated in a process often involving massive quenching and high cooling rates will be a mixture of $\alpha$-crystalline and mesomorphic phase, giving room for post-crystallization into the $\alpha$-crystalline phase of iPP under the right circumstances. Since the first paper of Schael [8] a number of authors have dealt with the specific case of extruded cast films [9-12] which only recently has received special attention by the group of Androsch [13-15]. Their work has demonstrated that not only the degree of $\alpha$-crystallinity is greatly reduced by quenching but also the morphology is changed from lamellar to a nodular structure. In another recent paper by De Santis et al. [16] not only the quenching process and mesophase formation, but also the possible transformation into the $\alpha$-crystalline phase at higher temperatures was studied.

The polymorphic nature of iPP which is capable of crystallizing in three different ordered forms of the $\alpha$-, $\beta$ - and $\gamma$-modifications $[17,18]$ next to the mesomorphic state plays a limited role under the solidification conditions of cast film extrusion. While at least some $\alpha$-nucleating agents are capable of inducing the $\gamma$-form as well [18] this modification does not form normally at high cooling rates. Formation of the $\beta$-modification should be avoided anyway when targeting transparency, but in absence of specific nucleating agents this modification would only be formed at very high chill roll temperatures $\left(>110^{\circ} \mathrm{C}\right)$.

The present study was directed at understanding processing and sterilization effects on the crystalline structures and the resulting cast film performance for both PP homopolymers and EP random copolymers, including versions with different $\alpha$-nucleating agents frequently used for improving transparency $[19,20]$. The influence of polymer parameters $\left(\mathrm{C}_{2}\right.$-content and randomness of EPcopolymers as defined by catalyst systems and polymerization parameters), nucleating agents and processing parameters (variation of the film thickness and the chill-roll temperature in the cast film extrusion line) were studied. Finally, the changes in optics were correlated to crystallinity and morphology variations assessed by differential scanning calorimetry (DSC), wide- and small-angle X-ray diffraction (WAXD/SAXS) and transmission electron microscopy (TEM).

\section{Experimental work}

Three series of experimental materials, all produced in a Borstar ${ }^{\mathrm{TM}}$ PP pilot plant unit with triethyl aluminium (TEAL) as co-catalyst and cyclohexyl methyl dimethoxysilane (CHMDMS, donor C) as external donor were investigated for this study:

- Series 'A' covers 7 EP random copolymers produced with a proprietary, non-commercial ZieglerNatta catalyst based on emulsion technology [21, 22] (C1). All grades had a reactor melt flow rate (MFR $230^{\circ} \mathrm{C} / 2.16 \mathrm{~kg}$ ) of $1,5 \mathrm{~g} / 10 \mathrm{~min}$, were visbroken with peroxide (2,5-dimethyl-2,5-di-(tert. butylperoxy)hexane, Trigonox 101, Akzo-Nobel, Germany) to an MFR of $8 \mathrm{~g} / 10 \mathrm{~min}$ and equipped with a standard additivation package (acid scavenger calcium stearate type 'SP', Faci, Italy; antioxidant blend Irganox B225, BASF AG, Germany; and synthetic silica as antiblocking agent, Sylobloc 45, Gracec Davison, USA).

- Series 'B' covers 6 EP random copolymers produced with a conventional high yield $4^{\text {th }}$ generation Ziegler-Natta catalyst (C2; Avant ZN M1, LyondellBasell, Italy) having an ethylene content between 0 and $5 \mathrm{wt} \%$. Visbreaking and additivation were the same as in series ' $A$ '.

- Series 'C' covers EP-copolymers with a C2-content of about $3.5 \mathrm{wt} \%$ based on three different catalyst systems from the same category. The grade made with catalyst C2 (FTIR randomness 0.920 ) had an MFR of about $1.5 \mathrm{~g} / 10 \mathrm{~min}$ and was subsequently visbroken to an MFR of $8 \mathrm{~g} / 10 \mathrm{~min}$, while the grades made with catalysts C1 (FTIR randomness 0.978 ) and $C 3$ (conventional high yield $4^{\text {th }}$ generation Ziegler-Natta catalyst, proprietary Borealis type, FTIR randomness 0.918 ) were neat reactor grades with an MFR of about $6 \mathrm{~g} / 10 \mathrm{~min}$. Different nucleating agents (A1 being an organophosphate, Adekastab NA-21, Adeka Palmaraole, France; A2 a sorbitol derivative, Millad 3988, Milliken, USA; and A3 a new carboxylic acid type, Hyperform HPN-68, Milliken, USA) for the $\alpha$-modification were added together with the same additive 
package as before, during the compounding step, testing against non-nucleated references.

For all PP materials, extrusion cast films of 50 and in some cases $130 \mu \mathrm{m}$ thickness were produced on a PM30 type laboratory extruder (Plastik Maschinenbau GmbH., Germany) with a coat-hanger slit die $200 \mathrm{~mm}$ wide and with a gap range of 0.55 to $0.6 \mathrm{~mm}$. The melt temperature was around $250^{\circ} \mathrm{C}$, the chill roll temperature was set at $15^{\circ} \mathrm{C}$ for series $\mathrm{A}$ and $\mathrm{B}$, while it was varied for series $\mathrm{C}(20,55$ and $90^{\circ} \mathrm{C}$ ).

After the extrusion, all films were optically characterized according to ASTM D 1003 using a Hazegard Plus instrument (BYK-Gardner $\mathrm{GmbH}$, Germany). The haze was chosen as most relevant parameter to assess differences in optics before and after sterilization. The measurements were done at least $96 \mathrm{~h}$ after film production or sterilization.

Steam sterilization was performed in a Systec D series machine (Systec Inc., USA). The samples were heated up at a heating rate of $5^{\circ} \mathrm{C} / \mathrm{min}$ starting from $23^{\circ} \mathrm{C}$. After having been kept for $30 \mathrm{~min}$ at $121^{\circ} \mathrm{C}$, they were removed immediately from the steam sterilizer and stored at room temperature till processed further.

Crystallinity and morphology of the films before and after sterilization were studied by DSC, WAXD/

SAXS and TEM, however not employing every method in each case. DSC measurements were carried out on a heat flux DSC 2920-CE (TA instruments, USA) on all samples before and after sterilization. Two heating scans and one cooling scan were done in between -10 and $210^{\circ} \mathrm{C}$ at a rate of $10^{\circ} \mathrm{C} / \mathrm{min}$. The analyzed samples had a weight of about $5 \mathrm{mg}$. The first heating cycle was considered to be the most interesting as it did not erase the history of thermal treated samples and was thus believed to give fairly reliable indications on the morphology of the investigated specimens. This is acceptable even though the test results are not as accurate as those provided by non destructive methods (e.g. WAXD). The melting temperature was determined as the maximum of the considered peak, and the melting enthalpies as the area under the respective peak.

Some selected samples were submitted to WAXD investigations at Vienna University of Technology and to TEM investigations at the Center for Electron Microscopy Graz, Austria. Wide-angle X-ray diffraction was done on the full films with a Philips X'Pert Pro instrument (Philips, Netherlands) using $\mathrm{CuK}_{\alpha}$ radiation in reflection mode. The peak integration for determining crystallinity was performed as reported before [23]. Small-angle X-ray scattering was performed on a Bruker AXS Nanostar instrument (Bruker, USA) with rotating anode source and a wavelength of $0.154 \mathrm{~nm}$ using a Histar 2D detector at a sample distance of $105 \mathrm{~cm}$.

For TEM, ultrathin sections of sample specimens contrasted with ruthenium tetroxide to allow differentiation between regions of high and low crystallinity were prepared [24]. Images were recorded on a Tecnai $G^{2} 12$ from FEI, USA, equipped with a CCD camera (Gatan Bioscan, Gatan Inc., USA) at $100 \mathrm{kV}$ acceleration voltage.

Ethylene content and the degree of randomness of comonomer insertion were determined by FTIR spectroscopy on a Spectrometer System 2000 (Perkin Elmer, USA) on compression moulded films by relating the peak heights at $733 \mathrm{~cm}^{-1}$ (representing the total $\mathrm{C}_{2}$ content) and the one at $720 \mathrm{~cm}^{-1}$ (representing the blocky insertion of ethylene) to each other [22]. Isotacticity was not determined, but from experience with the catalysts and donor employed a triad isotacticity $\left({ }^{13} \mathrm{C}-\mathrm{NMR}\right)$ of $\sim 97 \%$ can be assumed

\section{Results and discussion}

The basic composition and melting points determined on cast films are summarized for series 1 and 2 in Table 1, and for series 3 in Table 2 below. An example of the first heating cycle of a DSC thermogram of a freshly extruded cast film and sterilized film sample is provided in Figure 1 for one of the homopolymers from series A and for one of the EPcopolymers from series $\mathrm{C}$. The main challenge in this evaluation is to fix the baseline of the DSC traces in a reproducible way and the split between the two peaks appearing after sterilization, which for simplicity was done by taking the baseline as the line between the first minimum points to the left and the right of the peak and the split between two peaks as a vertical section at the minimum between the two peaks.

Two effects are immediately obvious from the first two tables: The rather linear reduction of melting point and enthalpy with increasing $\mathrm{C}_{2}$ content for series A and B (presented in Figure 2), and the fact 
Table 1. Basic properties of the polymers from series A and B (melting point from DSC on cast film before sterilization, enthalpy before and after sterilization)

\begin{tabular}{|c|c|c|c|c|c|c|c|c|}
\hline \multirow[b]{2}{*}{$\begin{array}{l}\text { Sample } \\
\text { number }\end{array}$} & \multirow{2}{*}{$\begin{array}{c}\text { Catalyst } \\
\text { type }\end{array}$} & \multirow{2}{*}{$\begin{array}{c}\text { MFR } \\
230^{\circ} \mathrm{C} / 2,16 \mathrm{~kg} \\
{[\mathrm{~g} / 10 \mathrm{~min}]}\end{array}$} & \multirow{2}{*}{$\begin{array}{c}\mathrm{C}_{2} \text { FTIR } \\
{[\mathrm{wt} \%]}\end{array}$} & \multirow{2}{*}{$\begin{array}{c}\text { Randomness } \\
\text { FTIR } \\
{[-]} \\
\end{array}$} & \multirow[b]{2}{*}{$\begin{array}{l}\mathbf{T}_{\mathbf{m}} \\
\left.{ }^{\circ} \mathbf{C}\right]\end{array}$} & \multicolumn{3}{|c|}{$H_{m}$ (heat 1) } \\
\hline & & & & & & $\begin{array}{l}\text { fresh } \\
{[\mathrm{J} / \mathrm{g}]}\end{array}$ & $\begin{array}{c}\text { sterilized } \\
{[\mathbf{J} / \mathbf{g}]}\end{array}$ & $\begin{array}{l}\text { Delta } \\
{[\mathrm{J} / \mathrm{g}]}\end{array}$ \\
\hline $\mathrm{A} / 1$ & emulsion & 8.0 & 0.0 & not def. & 162.9 & 100.7 & 100.9 & 0.2 \\
\hline $\mathrm{A} / 2$ & emulsion & 7.9 & 1.6 & 0.952 & 153.8 & 95.3 & 95.5 & 0.2 \\
\hline $\mathrm{A} / 3$ & emulsion & 7.5 & 2.4 & 0.972 & 146.6 & 87.9 & 90.3 & 2.4 \\
\hline $\mathrm{A} / 4$ & emulsion & 7.5 & 2.8 & 0.977 & 145.0 & 84.7 & 87.5 & 2.8 \\
\hline $\mathrm{A} / 5$ & emulsion & 8.2 & 3.5 & 0.979 & 144.0 & 83.7 & 85.1 & 1.4 \\
\hline $\mathrm{A} / 6$ & emulsion & 8.6 & 4.3 & 0.967 & 138.2 & 76.7 & 78.7 & 2.0 \\
\hline $\mathrm{A} / 7$ & emulsion & 8.4 & 5.2 & 0.958 & 132.3 & 68.5 & 73.8 & 5.3 \\
\hline $\mathrm{B} / 1$ & standard & 8.6 & 0.0 & not def. & 163.7 & 101.3 & 102.5 & 1.2 \\
\hline $\mathrm{B} / 2$ & standard & 7.4 & 1.6 & 0.913 & 154.7 & 94.1 & 96.0 & 1.9 \\
\hline $\mathrm{B} / 3$ & standard & 7.6 & 2.4 & 0.941 & 147.4 & 88.5 & 92.2 & 3.7 \\
\hline $\mathrm{B} / 4$ & standard & 8.5 & 3.3 & 0.915 & 145.2 & 83.3 & 88.4 & 5.1 \\
\hline $\mathrm{B} / 5$ & standard & 7.4 & 4.3 & 0.918 & 140.9 & 80.5 & 84.5 & 4.0 \\
\hline $\mathrm{B} / 6$ & standard & 7.2 & 5.0 & 0.900 & 136.3 & 75.1 & 80.9 & 5.8 \\
\hline
\end{tabular}

Table 2. Basic properties of the polymers from series $\mathrm{C}\left(\mathrm{C}_{2} 3.5 \mathrm{wt} \%\right.$; visbroken grades indicated by ' $\mathrm{CR}$ ' for 'controlled rheology'; melting point from DSC on cast film processed at different chill roll temperatures before sterilization)

\begin{tabular}{|c|c|c|c|c|c|c|c|}
\hline \multirow{2}{*}{$\begin{array}{l}\text { Sample num- } \\
\text { ber }\end{array}$} & \multirow{2}{*}{$\begin{array}{l}\text { Catalyst } \\
\text { type }\end{array}$} & \multirow{2}{*}{$\begin{array}{c}\text { MFR } \\
230^{\circ} \mathrm{C} / 2,16 \mathrm{~kg} \\
\text { [g/10 min] }\end{array}$} & \multirow{2}{*}{$\begin{array}{c}\text { Reactor or CR } \\
\text { type }\end{array}$} & \multirow{2}{*}{ Nucleation } & \multicolumn{3}{|c|}{$\mathbf{T}_{\mathrm{m}}\left[{ }^{\circ} \mathrm{C}\right]$ at chill roll temperature } \\
\hline & & & & & $20^{\circ} \mathrm{C}$ & $55^{\circ} \mathrm{C}$ & $90^{\circ} \mathrm{C}$ \\
\hline $\mathrm{C} / 1$ & $\mathrm{C} 2$ & 8.2 & CR & No & 143.1 & 144.5 & 146.3 \\
\hline $\mathrm{C} / 2$ & $\mathrm{C} 1$ & 5.7 & $\mathrm{RE}$ & No & 146.3 & 144.5 & 150.0 \\
\hline $\mathrm{C} / 3$ & $\mathrm{C} 3$ & 6.0 & $\mathrm{RE}$ & No & 142.0 & 143.3 & 145.3 \\
\hline $\mathrm{C} / 4$ & $\mathrm{C} 2$ & 7.8 & CR & A1 & 144.7 & 144.9 & 145.2 \\
\hline $\mathrm{C} / 5$ & $\mathrm{C} 1$ & 5.8 & $\mathrm{RE}$ & A1 & 146.7 & 148.1 & 149.5 \\
\hline $\mathrm{C} / 6$ & C3 & 6.4 & $\mathrm{RE}$ & A1 & 143.0 & 144.0 & 142.7 \\
\hline $\mathrm{C} / 7$ & $\mathrm{C} 2$ & 8.1 & CR & $\mathrm{A} 2$ & 144.1 & 145.2 & 145.8 \\
\hline $\mathrm{C} / 8$ & $\mathrm{C} 1$ & 5.6 & $\mathrm{RE}$ & $\mathrm{A} 2$ & 148.4 & 147.9 & 149.2 \\
\hline $\mathrm{C} / 9$ & $\mathrm{C} 3$ & 6.1 & $\mathrm{RE}$ & $\mathrm{A} 2$ & 143.1 & 143.8 & 140.5 \\
\hline $\mathrm{C} / 10$ & $\mathrm{C} 2$ & 7.9 & CR & A3 & 143.6 & 144.3 & 145.5 \\
\hline $\mathrm{C} / 11$ & $\mathrm{C} 1$ & 5.7 & $\mathrm{RE}$ & A3 & 147.7 & 147.8 & 149.0 \\
\hline $\mathrm{C} / 12$ & C3 & 6.2 & $\mathrm{RE}$ & A3 & 142.4 & 143.4 & 145.4 \\
\hline
\end{tabular}
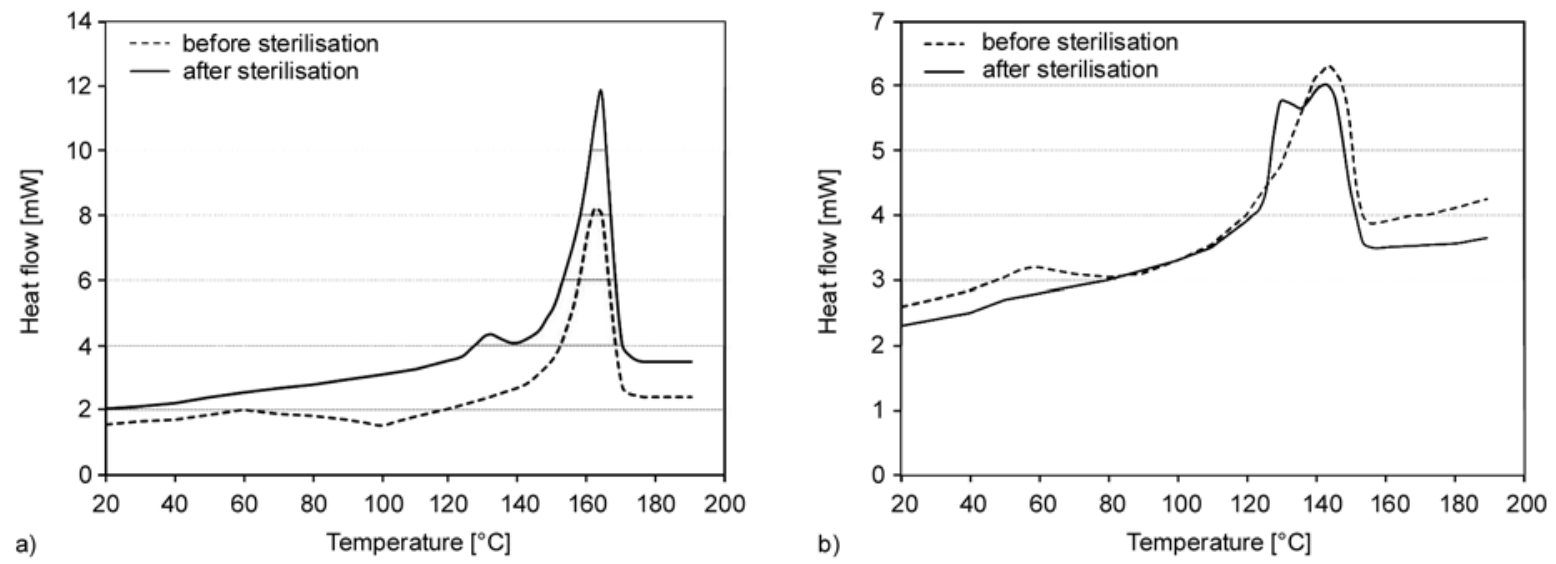

Figure 1. DSC thermograms recorded at $10 \mathrm{~K} / \mathrm{min}$ for (a) PP homopolymer A/1 (MFR 8,0) processed at a chill roll temperature of $15^{\circ} \mathrm{C}$, and (b) $\mathrm{EP}$ random copolymer $\mathrm{C} / 3$ (MFR 6,0 and 3,5 $\mathrm{wt} \% \mathrm{C} 2$ ) processed at a chill roll temperature of $55^{\circ} \mathrm{C}$; scans before and after sterilization 


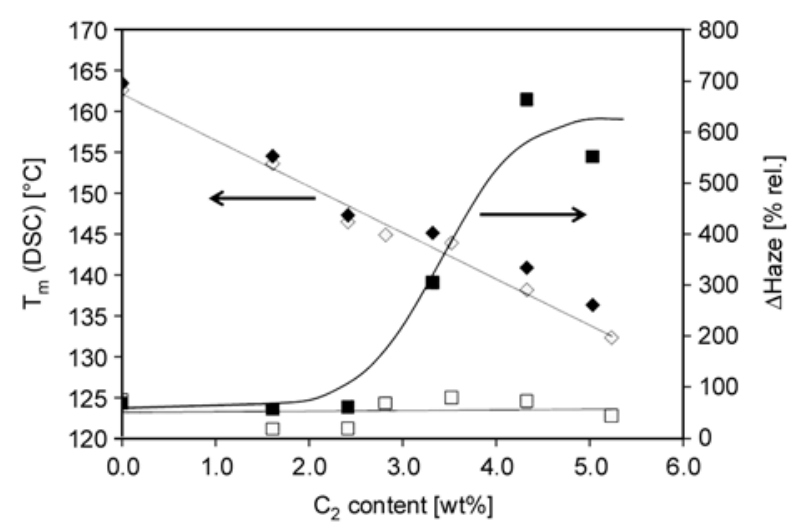

Figure 2. Changes in melting temperature and haze (cast film, $50 \mu \mathrm{m})$ in sterilization at $121^{\circ} \mathrm{C}$ depending on the $\mathrm{C}_{2}$-content for polymers from series $\mathrm{A}$ (high randomness, open symbols) and second series B (limited randomness, filled symbols)

that both nucleation and catalyst type co-influence the quenching effect achieved by reducing the chill roll temperature in series $\mathrm{C}$. Here, the chill roll temperature $\left(T_{\text {roll }}\right)$ was varied between 20 and $90^{\circ} \mathrm{C}$ to simulate cases of a:

(i) a highly amorphous transparent structure with moderate stiffness $\left(T_{\text {roll: }}: 20^{\circ} \mathrm{C}\right)$,

(ii) a stiff film also having good starting optics ( $T_{\text {roll: }}: 55^{\circ} \mathrm{C}$ ),

(iii) a maximum crystalline film $\left(T_{\text {roll }}: 90^{\circ} \mathrm{C}\right)$.

In the industrial practice of film processing, such variations are applied to balance film properties $[25,26]$, but the resulting crystal structures also define the long-term property evolution of the produced films. In an earlier paper from our group [27] the massive difference between injection moulded parts and cast films both in term of room tempera- ture ageing and sterilization (annealing) behaviour has been demonstrated already.

The comonomer influence in the first two series is clearly reflected in the optical changes during sterilization. As Figure 2 shows, the haze increase from this annealing process remains rather constant up to an ethylene content of about $2.5 \mathrm{wt} \%$ and then rises significantly for the polymers based on the conventional catalyst (B) while staying at a lower level $(<100 \%)$ for the emulsion catalyst based products with better randomness (A). The high numbers of up to $\sim 670 \%$ for the relative haze change should be considered together with the absolute values listed in Table 3. Only for the materials showing the strongest haze increase, $\mathrm{B} / 5$ and $\mathrm{B} / 6$, the film loses its transparency visibly with absolute haze value of $>15 \%$.

Figure 3 further illustrates the fact that this trend in haze increase generally goes together with differ-

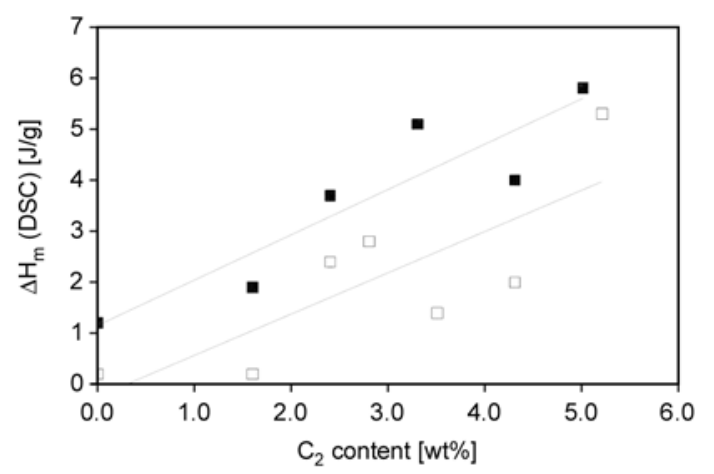

Figure 3. Changes in melting enthalpy in sterilization at $121^{\circ} \mathrm{C}$ depending on the $\mathrm{C}_{2}$-content for polymers from series A (high randomness, open symbols) and second series B (limited randomness, filled symbols)

Table 3. Ethylene content and randomness effects on haze of PP cast films of $50 \mu \mathrm{m}$ thickness produced at $15^{\circ} \mathrm{C}$ chill roll temperature (absolute values and change in sterilization) for polymers from series A and B

\begin{tabular}{|c|c|c|c|c|c|}
\hline \multirow[b]{2}{*}{ Number } & \multirow{2}{*}{$\begin{array}{c}\mathrm{C}_{2} \\
\text { FTIR } \\
{[\mathrm{wt} \%]}\end{array}$} & \multirow{2}{*}{$\begin{array}{c}\text { Randomness } \\
\text { FTIR } \\
{[-]}\end{array}$} & \multicolumn{3}{|c|}{ Haze $50 \mu \mathrm{m}$ film } \\
\hline & & & $\begin{array}{c}\text { fresh } \\
{[\%]}\end{array}$ & $\begin{array}{c}\text { sterilized } \\
{[\%]}\end{array}$ & $\begin{array}{c}\text { Delta } \\
\text { [\% rel.] }\end{array}$ \\
\hline $\mathrm{A} / 1$ & 0.0 & n.d. & 2.2 & 3.8 & 73 \\
\hline $\mathrm{A} / 2$ & 1.6 & 0.952 & 1.9 & 2.2 & 16 \\
\hline $\mathrm{A} / 3$ & 2.4 & 0.972 & 2.3 & 2.7 & 17 \\
\hline $\mathrm{A} / 4$ & 2.8 & 0.977 & 1.8 & 3.0 & 67 \\
\hline $\mathrm{A} / 5$ & 3.5 & 0.979 & 2.7 & 4.8 & 78 \\
\hline $\mathrm{A} / 6$ & 4.3 & 0.967 & 2.4 & 4.1 & 71 \\
\hline $\mathrm{A} / 7$ & 5.2 & 0.958 & 2.8 & 4.0 & 43 \\
\hline $\mathrm{B} / 1$ & 0.0 & n.d. & 2.4 & 4.0 & 67 \\
\hline $\mathrm{B} / 2$ & 1.6 & 0.913 & 2.2 & 3.4 & 55 \\
\hline $\mathrm{B} / 3$ & 2.4 & 0.941 & 2.0 & 3.2 & 60 \\
\hline $\mathrm{B} / 4$ & 3.3 & 0.915 & 1.9 & 7.7 & 305 \\
\hline $\mathrm{B} / 5$ & 4.3 & 0.918 & 2.1 & 16.1 & 667 \\
\hline $\mathrm{B} / 6$ & 5.0 & 0.900 & 2.4 & 15.7 & 554 \\
\hline
\end{tabular}




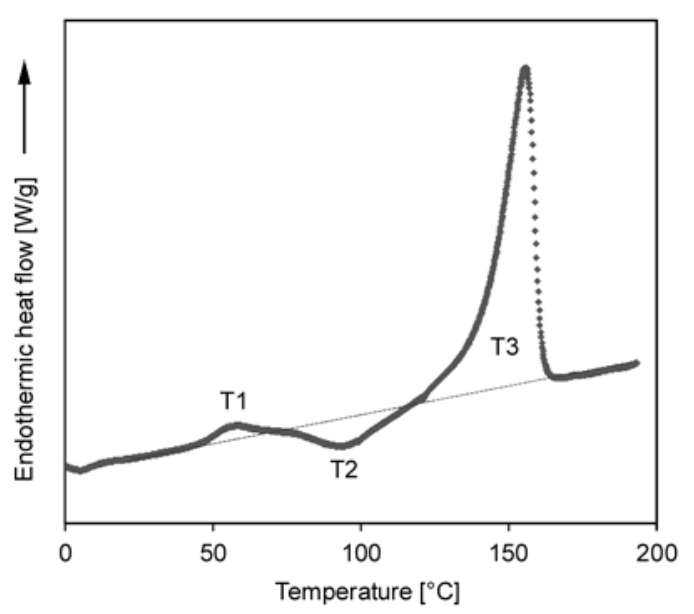

Figure 4. DSC thermogram (heat 1) recorded at $10 \mathrm{~K} / \mathrm{min}$ for a $1.6 \mathrm{wt} \%$ ethylene content film (polymer $\mathrm{B} / 2$ ) before sterilization

ences in the post-crystallization intensity as expressed by the increase of melting enthalpy. An acceptable correlation between haze and crystallinity changes is only achieved for the materials from series B.

For better understanding this phenomenon, the fraction of the melting enthalpy curve below the sterilization temperature of $121^{\circ} \mathrm{C}$ was calculated in relation to the total melting enthalpy. The slope change at $2.5 \mathrm{wt} \%$ found in Figure 2 could not quite be reproduced here, but the reason for this becomes obvious when taking a closer look at the DSC curve (heat 1) before sterilization as recorded for material $\mathrm{B} / 2$ (see Figure 4) which is rather typical.

Three peaks could be distinguished here, corresponding to three transitions [28]:

(i) an endothermic peak (T1) with its maximum at around $60^{\circ} \mathrm{C}$,

(ii) an exothermic peak (T2) with its maximum at around $100^{\circ} \mathrm{C}$,

(iii) a large endothermic peak (T3) with its maximum at around $160^{\circ} \mathrm{C}$ in the case of the homopolymer (resp. $156^{\circ} \mathrm{C}$ for the polymer considered here). Peak T1 probably is just the result of a superposition of the post-crystallisation peak $\mathrm{T} 2$ and the melting peak $\mathrm{T} 3$, with the exothermic peak $\mathrm{T} 2$ resulting from post-crystallization due to the increased mobility of the crystalline phase starting at $\sim 50^{\circ} \mathrm{C}$ [29].

With this increased mobility, further crystallization of the quenched film takes place both in the form of lamellar thickening and in the formation of secondary crystals in the amorphous regions between the lamellae $[7,28]$. The rearrangement of the amor- phous part - and probably part of the mesomorphic fraction as well - causes a crystallization peak. Evaluation of the area of this peak T2 showed a linear decrease of this area with the increase in ethylene content. This area evaluation is not exact as the superposition of the two peaks leads to high error but it is representative of the evolution. The increase in ethylene content therefore improves the optical properties of the films before sterilization by reducing haze. However it also increases the difference in the optical properties of the films with sterilization and encourages secondary crystallization; this increased 'quenchability' of PP grades with reduced regularity due to stereodefects and/or comonomer incorporation has already been demonstrated before by La Carrubba et al. [30].

After sterilization, the DSC analysis of the films reveals a double melting peak as already evidenced in Figure 1. Surprisingly, the first peak of these is always at the same temperature of $\sim 131^{\circ} \mathrm{C}$, indicating the secondary crystals generated in the sterilization step being rather independent of the ethylene content. Figure 5 gives the partial enthalpies for the primary (high $T_{\mathrm{m}}$, depending on $\mathrm{C}_{2}$ content) and secondary (low $T_{\mathrm{m}}, 131^{\circ} \mathrm{C}$ ) crystallization fractions in the films from the B-series (conventional catalyst, limited randomness). The qualitative correlation of the latter part to the haze increase in Figure 3 is quite striking - at the highest comonomer content the chain irregularities obviously even reduce the capacity for post-crystallization, in line with the overall crystallization speed reduction found for such materials before [1]. A possible explanation for the limited correlation between haze and crystallinity changes for material series A mentioned

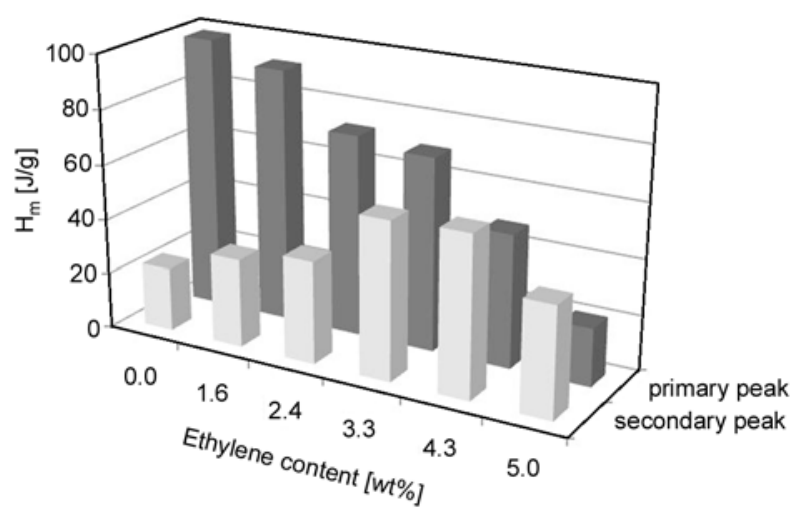

Figure 5. Partial melting enthalpy for primary and secondary crystallization melting for the sterilized cast films from series B 
above could be the changing relation between primary and secondary crystals with changing comonomer content.

In series $\mathrm{C}$, where the focus was on processing and nucleation effects, the optical properties were found to deteriorate with increasing the chill roll temperatures as a result of an increase in crystallinity as to be expected from literature [31]. When exemplified with material C/1 (non-nucleated sample), this feature corresponds to an enhancement of the melt enthalpy from $64.0 \mathrm{~J} / \mathrm{g}$ for a chill roll temperature of $20^{\circ} \mathrm{C}$, to $76.1 \mathrm{~J} / \mathrm{g}$ for a chill roll temperature of $55^{\circ} \mathrm{C}$, to $82.7 \mathrm{~J} / \mathrm{g}$ for a chill roll temperature of $90^{\circ} \mathrm{C}$. Two factors play a parallel role in this effect for high chill roll temperatures, especially in absence of a nucleating agent:

(i) the reduction of the rate of crystallization allowing the crystallites to grow to large spherulites, in turn increasing the haze (see Figure 6), and

(ii) a reduction of the amount of mesomorphic phase in the system [32].

Even though the optical performance worsened with the chill roll temperature, this picture was

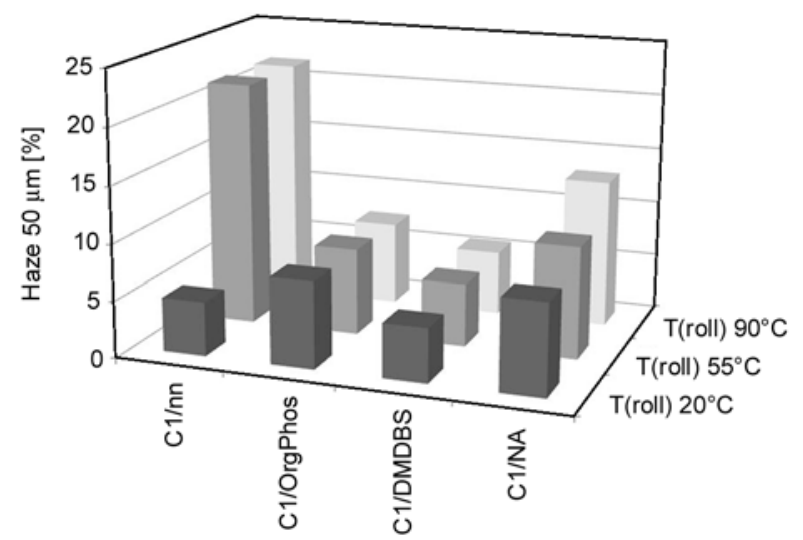

Figure 6. Nucleation and processing effects on haze of PP cast films of $50 \mu \mathrm{m}$ thickness before sterilization (chill roll temperature variation from 20 to $90^{\circ} \mathrm{C}$ ) for one of the polymers from series $\mathrm{C}$ (catalyst C1) notably influenced by nucleation as also highlighted in Table 4. Both the organophosphate and the sorbitol derivative, i.e. a particulate and a soluble nucleating agent, are obviously capable of stabilizing the transparency at an acceptable level by increasing the number of nuclei in the system and limiting spherulite size. The higher overall crystallization rate promoted by heterogeneous nucleation [15] also results in a lower sensitivity of $\alpha$-nucleated samples to cooling rates. This result suggests that the morphology and thus the optical performance of random copolymers can be controlled by $\alpha$ nucleation rather independently of the conversion temperature.

The relative change in haze as a function of the chill roll temperature of up to $80 \%$ starting from a very low haze level of around 3 to $6 \%$ for the 'worst' nucleating agent tested contrasts sharply to a variation of up to $670 \%$ for non-nucleated samples as a consequence of the processing conditions as already mentioned earlier. The low difference in haze between a chill roll temperature of 55 and $90^{\circ} \mathrm{C}$ suggests that the crystallization speed of the studied polymer is not overruled by processing parameters, while the opposite holds for chill-roll temperatures of $20^{\circ} \mathrm{C}$ independently of the material under investigation.

Table 4 also gives the difference in haze caused by sterilization; these variations are more or less pronounced depending on the initial crystalline state of the grade. For the medium chill roll temperature of $55^{\circ} \mathrm{C}$ the situation is illustrated in Figure 7: The different interaction between polymer and nucleating agent for the materials based on the emulsion catalyst $\mathrm{C} 1$ (higher randomness) allows better haze values after sterilization despite slightly higher ones before, at least for two of the nucleating agents. Quenched films obtained with a chill roll temperature of $20^{\circ} \mathrm{C}$ are far more sensitive to a heat treat-

Table 4. Nucleation and chill roll temperature effects on haze of PP cast films of $50 \mu \mathrm{m}$ thickness (absolute values and change in sterilization) for two different polymers from series $\mathrm{C}$ (same as in Figure 6)

\begin{tabular}{|c|c|c|c|c|c|c|c|c|}
\hline \multirow{2}{*}{$\begin{array}{l}\text { Sample } \\
\text { number }\end{array}$} & \multirow{2}{*}{$\begin{array}{c}\text { Catalyst } \\
\text { type }\end{array}$} & \multirow{2}{*}{ Nucl. type } & \multicolumn{2}{|c|}{ Haze $20^{\circ} \mathrm{C}$} & \multicolumn{2}{|c|}{ Haze $55^{\circ} \mathrm{C}$} & \multicolumn{2}{|c|}{ Haze $90^{\circ} \mathrm{C}$} \\
\hline & & & fresh & Delta & fresh & Delta & fresh & Delta \\
\hline $\mathrm{C} / 2$ & \multirow{4}{*}{$\mathrm{C} 1$} & No & 4.8 & 2.3 & 21.7 & 1.4 & 21.7 & 1.4 \\
\hline $\mathrm{C} / 5$ & & A1 & 7.7 & 0.0 & 7.7 & 0.9 & 7.4 & 1.9 \\
\hline $\mathrm{C} / 8$ & & A2 & 4.8 & 2.5 & 5.6 & 1.6 & 5.7 & 7.8 \\
\hline $\mathrm{C} / 11$ & & A3 & 8.1 & 4.5 & 9.9 & 1.5 & 13.1 & 2.1 \\
\hline $\mathrm{C} / 3$ & \multirow{4}{*}{$\mathrm{C} 3$} & No & 4.7 & 1.8 & 19.2 & 0.9 & 25.3 & 0.5 \\
\hline $\mathrm{C} / 6$ & & A1 & 6.8 & 3.2 & 6.1 & 5.3 & 6.5 & 1.7 \\
\hline $\mathrm{C} / 9$ & & $\mathrm{~A} 2$ & 4.2 & 6.1 & 4.7 & 4.5 & 5.3 & 9.1 \\
\hline $\mathrm{C} / 12$ & & A3 & 6.7 & 3.7 & 8.4 & 0.8 & 11.6 & 1.6 \\
\hline
\end{tabular}




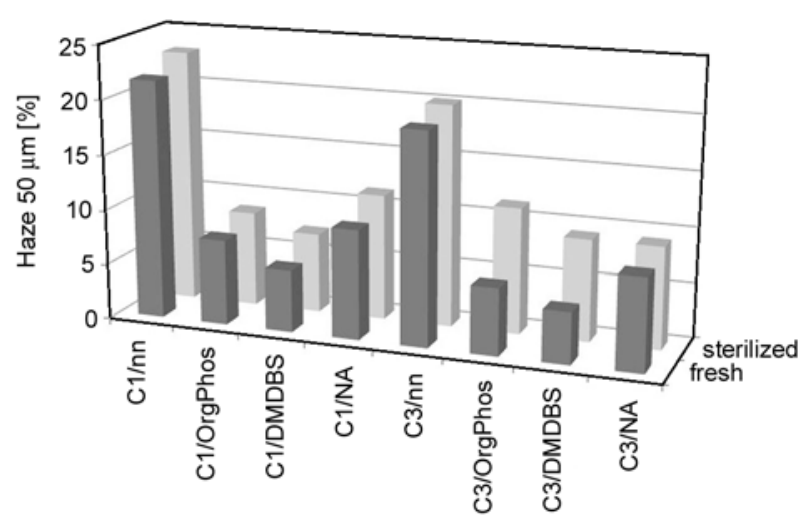

Figure 7. Nucleation and sterilization effects on haze of PP cast films of $50 \mu \mathrm{m}$ thickness (chill roll temperature $55^{\circ} \mathrm{C}$ ) for two different polymers from series $\mathrm{C}$ (catalysts $\mathrm{C} 2$ and $\mathrm{C} 3$, same $\mathrm{C}_{2}$ content but different randomness)

ment than more crystalline samples manufactured at a chill-roll temperature of $90^{\circ} \mathrm{C}$. They undergo the largest reorganization and lamellar thickening with sterilization, as a combination of annealing and post-crystallization effects as also documented in the literature [6, 7, 9, 27-29].

The occurrence of lamellar thickening in post-crystallization - as a result of a reduction of the magnitude on the interfacial free energy [7] - could be confirmed by TEM (see Figur 8) and in WAXD/ SAXS analysis (see Table 5). Using the example of a nucleated sample processed at a chill-roll temper-

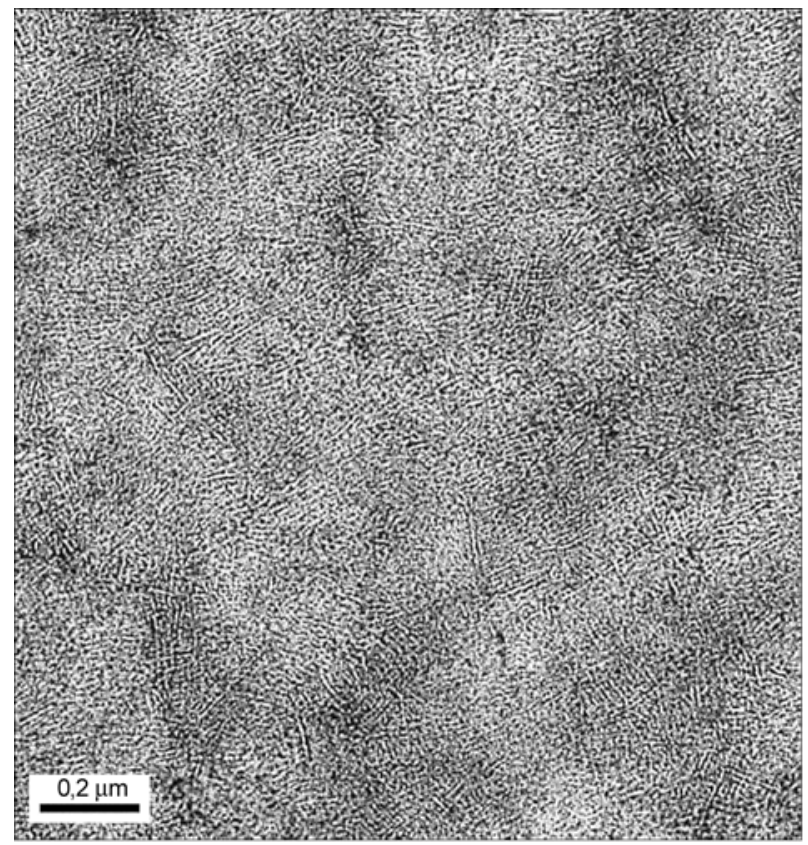

a) ature of $90^{\circ} \mathrm{C}$, it becomes obvious that a heat treatment at $121^{\circ} \mathrm{C}$ for $30 \mathrm{~min}$ promotes the formation of thicker lamella and leads to a denser network of crystalline structures. The X-ray data moreover show two very interesting phenomena:

(i) the crystallinity increase in sterilization is significant only for the non-nucleated sample, providing an additional explanation for the reduced haze increase in nucleated materials (see again Table 3), (ii) in contrast to expectations from theory (which predicts an increase due to the higher crystallization temperature [33]), nucleation does not affect the lamellar thickness in cast-film processing.

In detail, the correlation between lamellar thickening and haze increase remains a subject of speculation. It is difficult understand either how a change in crystallinity on the nm-scale should affect light scattering, but secondary effects like surface distortion and roughness might play a role here.

Table 5. Results of WAXD/SAXS analysis of films from materials $\mathrm{C} / 3$ and $\mathrm{C} / 6$ (catalyst $\mathrm{C} 3$, MFR 6, $3.5 \mathrm{wt} \%$ $\mathrm{C} 2$ ) before and after sterilization; overall crystallinity from WAXD and long period L from SAXS given

\begin{tabular}{|l|l|c|c|}
\hline \multicolumn{1}{|c|}{ Sample } & \multicolumn{1}{c|}{ State } & $\mathbf{X}_{\mathbf{c r}}[\mathbf{\%}]$ & $\mathbf{L}[\mathbf{n m}]$ \\
\hline $\mathrm{C} / 3$, non-nucleated & extruded $90^{\circ} \mathrm{C}$ & 56 & 11,3 \\
\hline $\mathrm{C} / 3$, non-nucleated & sterilized $121^{\circ} \mathrm{C}$ & 64 & 15,1 \\
\hline $\mathrm{C} / 6$, nucleated & extruded $90^{\circ} \mathrm{C}$ & 61 & 11,5 \\
\hline $\mathrm{C} / 6$, nucleated & sterilized $121^{\circ} \mathrm{C}$ & 63 & 15,2 \\
\hline
\end{tabular}

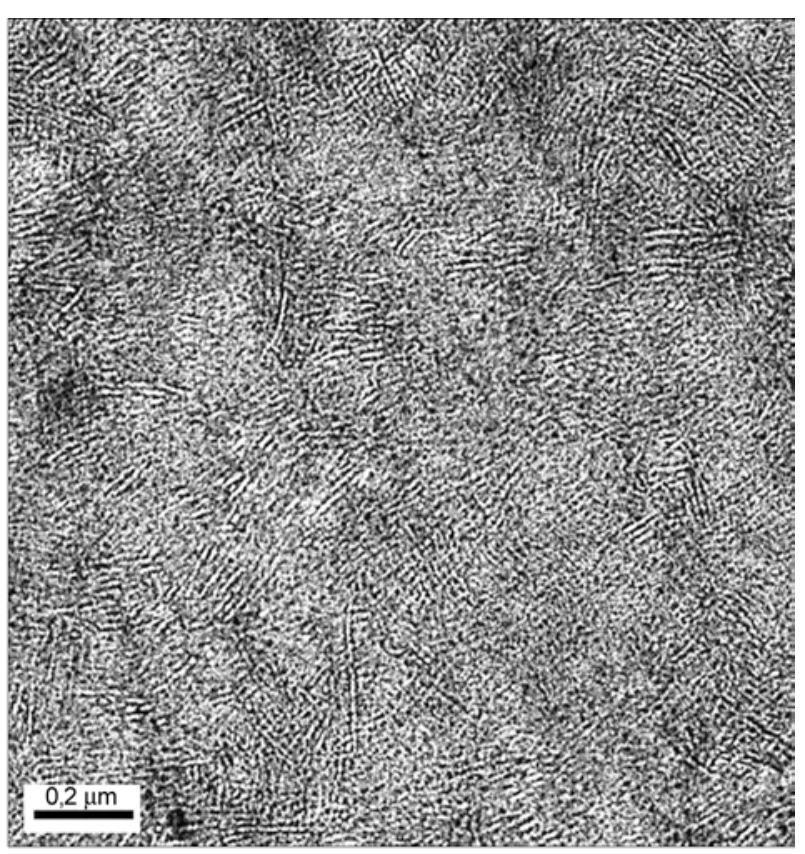

b)

Figure 8. TEM images of the lamellar morphology of material $\mathrm{C} / 6$ (catalyst $\mathrm{C} 3$, MFR $6,3.5 \mathrm{wt} \% \mathrm{C}_{2}$ ) from cast film extruded at chill roll temperature of $90^{\circ} \mathrm{C}$ before (a) and after (b) sterilization at $121^{\circ} \mathrm{C}$; scale bar dimension $200 \mathrm{~nm}$ 


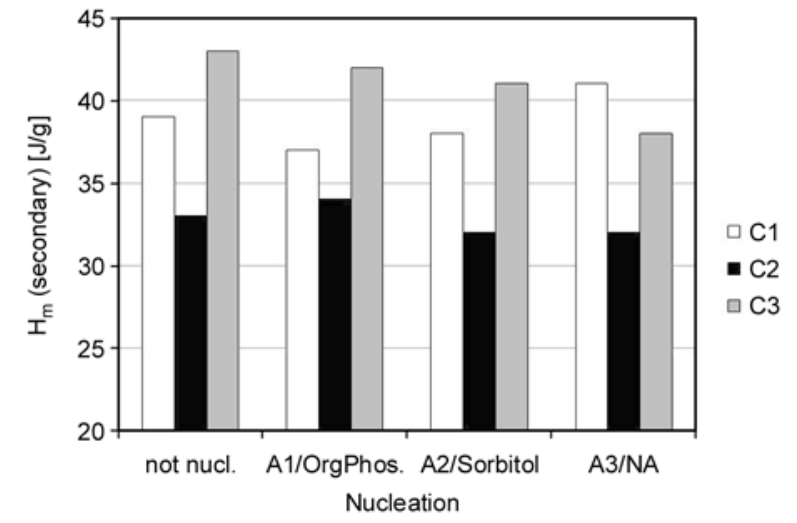

Figure 9. Melting enthalpy of secondary crystallization after sterilization for polymers from series $\mathrm{C}$ extruded at $T_{\text {roll }}=20^{\circ} \mathrm{C}$

Also for the third series an attempt to correlate haze variations with crystallinity changes before and after sterilization was made using the DSC traces of the first heat after sterilization. As explained before, a double peak was found with high reproducibility for all samples. In contrast to the results shown in Figure 5, where a clear correlation of both primary and secondary peak with the comonomer content could be established, the situation was found to be far more complex here. In general, the relative amount (enthalpy) of the secondary crystallization was higher for the $20^{\circ} \mathrm{C}$ chill roll temperatures than for the $90^{\circ} \mathrm{C}$ chill roll temperature, confirming the increased mobility in more strongly quenched films observed for PP homopolymers before [27].

Another clear difference among the materials results from the catalyst choice; the lower area of secondary crystallization for materials based on the emulsion catalyst $\mathrm{C} 1$ for the quenched films was quite obvious (see Figure 9). One possible reason is the higher melting point mentioned above for these films which leads to less reorganization due to melting. Another effect could also be the decrease of lamellar thickening with the increase in randomly distributed ethylene content as the lamellae are already thick enough and could not thicken further. The influence of the nucleating agents on the secondary crystallization is however not visible in the DSC analysis as the areas of all the films for a given polymerization method are nearly constant. This is true for all three chill roll temperatures.

\section{Conclusions}

We investigated the structure of EP random copolymer films before and after sterilization at $121^{\circ} \mathrm{C}$ for 30 minutes by DSC, TEM, POM and WAXD/SAXS to explain the changes in optical properties (haze) of extrusion cast films. In addition to the comonomer content and the polymer structure (as a function of polymerization conditions and visbreaking), nucleating agents and extrusion conditions were changed. Three series of films were studied, varying catalyst type and comonomer content in the first two series, and catalyst, molecular weight distribution, nucleation and processing conditions in the third one. The findings clearly show that a combination of homogeneously randomized comonomer distribution and nucleation can partly inhibit lamellar thickening in sterilization, thus preserving high transparency even after a heat treatment.

In detail, attention has to be paid to the combined effects of physical ageing and post-crystallization, which both are affected by the chain regularity. The appearance of a rather constant secondary melting peak in DSC at a temperature of $10 \mathrm{~K}$ above the sterilization temperature clearly points to the existence of secondary crystalline structures postulated before by several authors [7, 27, 28]. More extensive investigations, especially using the possibilities of X-ray diffraction, will be required to develop a more complete understanding.

\section{References}

[1] Gahleitner M., Jääskeläinen P., Ratajski E., Paulik C., Reussner J., Wolfschwenger J., Neiß1 W.: Propyleneethylene random copolymers: Comonomer effects on crystallinity and application properties. Journal of Applied Polymer Science, 95, 1073-1081 (2005). DOI: $10.1002 /$ app. 21308

[2] Thorat H. B., Prabhu C. S., Suresh K. K., Pandya M. $\mathrm{V}$ : $\gamma$-ray-induced degradation in ethylene-propylene copolymer. Journal of Applied Polymer Science, 59, 1769-1773 (1996).

DOI: $10.1002 /(\mathrm{SICI}) 1097-4628(19960314) 59: 11<1769$ $\because$ AID-APP13>3.0.CO;2-P

[3] Resch K., Wallner G. M., Teichert C., Maier G., Gahleitner M.: Optical properties of highly transparent polypropylene cast films: Influence of material structure, additives, and processing conditions. Polymer Engineering and Science, 46, 520-531 (2006). DOI: $10.1002 /$ pen.20503 
[4] Gezovich D. M., Geil P. H.: Deformation and aging of quenched polypropylene. Polymer Engineering and Science, 8, 210-215 (1986).

DOI: $10.1002 /$ pen.760080306

[5] Vittoria V.: Investigation of the ageing of isotactic polypropylene via transport properties. Polymer, 29, 1118-1123 (1988).

DOI: $10.1016 / 0032-3861(88) 90025-0$

[6] Piccarolo S.: Ageing of isotactic polypropylene due to morphology evolution, experimental limitations of realtime density measurements with a gradient column. Polymer, 47, 5610-5622 (2006).

DOI: $10.1016 /$ j.polymer.2005.03.128

[7] Marand H., Alizadeh A., Sohn S., Xu J., Farmer R., Prabhu V., Cronin S., Velikov V.: A model for the physical aging of semicrystalline polymers above $T_{\mathrm{g}}$ : Secondary crystallization induced constraining effects. Proceedings of SPE ANTEC 59, Vol. 2, 1856-1859 (2001).

[8] Schael G. W.: A study of the morphology and physical properties of polypropylene films. Journal of Applied Polymer Science, 10, 901-915 (1966).

DOI: 10.1002/app.1966.070100607

[9] O'Kane W. J., Young R. J., Ryan A. J.: The effect of annealing on the structure and properties of isotactic polypropylene films. Journal of Macromolecular Science Part B: Physics, 34, 427-458 (1995).

DOI: $10.1080 / 00222349508219502$

[10] Ferrer-Balas D., Maspoch M. L., Martinez A. B., Santana O. O.: Influence of annealing on the microstructural, tensile and fracture properties of polypropylene films. Polymer, 42, 1697-1705 (2001).

DOI: 10.1016/S0032-3861(00)00487-0

[11] Marega C., Causin V., Marigo A.: A SAXS-WAXD study on the mesomorphic- $\alpha$ transition of isotactic polypropylene. Journal of Applied Polymer Science, 109, 32-37 (2008).

DOI: $10.1002 / a p p .28017$

[12] Polo-Corpa M. J., Benavente R., Velilla T., Quijada R., Pérez E., Cerrada M. L.: Development of the mesomorphic phase in isotactic propene/higher $\alpha$-olefin copolymers at intermediate comonomer content and its effect on properties. European Polymer Journal, 46, 1345-1354 (2010).

DOI: $10.1016 /$ j.eurpolymj.2010.03.014

[13] Mileva D., Androsch R., Radusch H-J.: Effect of cooling rate on melt-crystallization of random propyleneethylene and propylene-1-butene copolymers. Polymer Bulletin, 61, 643-654 (2008).

DOI: $10.1007 / \mathrm{s} 00289-008-0979-6$

[14] Androsch R.: In situ atomic force microscopy of the mesomorphic-monoclinic phase transition in isotactic polypropylene. Macromolecules, 41, 533-535 (2008). DOI: $10.1021 / \mathrm{ma} 702334 \mathrm{q}$
[15] Mileva D., Zia Q., Androsch R., Radusch H-J., Piccarolo S.: Mesophase formation in poly(propyleneran-1-butene) by rapid cooling. Polymer, 50, 54825489 (2009).

DOI: $10.1016 /$ j.polymer.2009.09.064

[16] De Santis F., Adamovsky S., Titomanlio G., Schick C.: Scanning nanocalorimetry at high cooling rate of isotactic polypropylene. Macromolecules, 39, 2562-2567 (2006).

DOI: $10.1021 / \mathrm{ma} 052525 \mathrm{n}$

[17] Lotz B., Wittmann J. C., Lovinger A. J.: Structure and morphology of poly(propylenes): A molecular analysis. Polymer, 37, 4979-4992 (1996).

DOI: 10.1016/0032-3861(96)00370-9

[18] Foresta T., Piccarolo S., Goldbeck-Wood G.: Competition between $\alpha$ and $\gamma$ phases in isotactic polypropylene: Effects of ethylene content and nucleating agents at different cooling rates. Polymer, 42, 1167-1176 (2001).

DOI: $10.1016 / \mathrm{S} 0032-3861(00) 00404-3$

[19] Macauley N. J., Harkin-Jones E. M. A., Murphy W. R.: The influence of nucleating agents on the extrusion and thermoforming of polypropylene. Polymer Engineering and Science, 38, 662-670 (1998).

DOI: 10.1002/pen.10214

[20] Bernland K., Tervoort T., Smith P.: Phase behavior and optical- and mechanical properties of the binary system isotactic polypropylene and the nucleating/clarifying agent 1,2,3-trideoxy-4,6:5,7-bis- $O$-[(4-propylphenyl) methylene]-nonitol. Polymer, 50, 2460-2464 (2009).

DOI: 10.1016/j.polymer.2009.03.010

[21] Abboud M., Denifl P., Reichert K-H.: Study of the morphology and kinetics of novel Ziegler-Natta catalysts for propylene polymerization. Journal of Applied Polymer Science, 98, 2191-2200 (2005).

DOI: 10.1002/app.22412

[22] Grein C., Schedenig T.: Polyolefin compositions having improved optical and mechanical properties. WO 2009/027389, Germany (2007).

[23] Koch T., Seidler S., Halwax E., Bernstorff S.: Microhardness of quenched and annealed isotactic polypropylene. Journal of Materials Science, 42, 5318-5326 (2007).

DOI: $10.1007 / \mathrm{s} 10853-006-0960-4$

[24] Zia Q., Androsch R., Radusch H-J., Ingolic E.: Crystal morphology of rapidly cooled isotactic polypropylene: A comparative study by TEM and AFM. Polymer Bulletin, 60, 791-798 (2008).

DOI: $10.1007 / \mathrm{s} 00289-008-0908-8$

[25] Cotto D., Duffo P., Haudin J. M.: Cast film extrusion of polypropylene films. International Polymer Processing, 4, 103-113 (1989). 
[26] Duffo P., Monasse B., Haudin J. M.: Influence of stretching and cooling conditions in cast film extrusion of PP films. International Polymer Processing, 5, 272-283 (1990).

[27] Gahleitner M., Fiebig J., Wolfschwenger J., Dreiling G., Paulik C.: Post-crystallization and physical aging of polypropylene: Material and processing effects. Journal of Macromolecular Science Part B: Physics, 41, 833-849 (2002).

DOI: $10.1081 / \mathrm{MB}-120013068$

[28] Alberola N., Fugier M., Petit D., Fillon B.: Microstructure of quenched and annealed films of isotactic polypropylene. Journal of Materials Science, 30, 1187-1195 (1995).

DOI: $10.1007 / \mathrm{BF} 00356118$

[29] Agarwal M. K., Schultz J. M.: The physical aging of isotactic polypropylene. Polymer Engineering and Science, 21, 776-781 (1981).

DOI: $10.1002 /$ pen. 760211206
[30] La Carrubba V., Piccarolo S., Brucato V.: Crystallization kinetics of iPP: Influence of operating conditions and molecular parameters. Journal of Applied Polymer Science, 104, 1358-1367 (2007).

DOI: 10.1002/app.25871

[31] Resch K., Wallner G. M., Teichert C., Gahleitner M.: Highly transparent polypropylene cast films: Relationships between optical properties, additives, and surface structure. Polymer Engineering and Science, 47, 1021-1032 (2007).

DOI: $10.1002 /$ pen.20781

[32] Martorana A., Piccarolo S., Schichilone F.: The X-ray determination of the amounts of the phases in samples of isotactic poly(propylene) quenched from the melt at different cooling rates. Macromolecular Chemistry and Physics, 198, 597-604 (1997).

DOI: 10.1002/macp.1997.021980231

[33] Pukánszky B., Mudra I., Staniek P.: Relation of crystalline structure and mechanical properties of nucleated polypropylene. Journal of Vinyl and Additive Technology, 3, 53-57 (1997).

DOI: $10.1002 / \mathrm{vnl} .10165$ 